\title{
Price-Based Demand Side Response Programs and Their Effectiveness on the Example of TOU Electricity Tariff for Residential Consumers
}

\author{
Jerzy Andruszkiewicz (D), Józef Lorenc and Agnieszka Weychan * (D) \\ Institute of Electric Power Engineering, Poznan University of Technology, 60-965 Poznan, Poland; \\ jerzy.andruszkiewicz@put.poznan.pl (J.A.); jozef.lorenc@put.poznan.pl (J.L.) \\ * Correspondence: agnieszka.weychan@put.poznan.pl
}

check for

updates

Citation: Andruszkiewicz, J.; Lorenc,

J.; Weychan, A. Price-Based Demand

Side Response Programs and Their

Effectiveness on the Example of TOU Electricity Tariff for Residential

Consumers. Energies 2021, 14, 287.

https://doi.org/doi:10.3390/

en14020287

Received: 25 November 2020

Accepted: 5 January 2021

Published: 7 January 2021

Publisher's Note: MDPI stays neutral with regard to jurisdictional clai$\mathrm{ms}$ in published maps and institutional affiliations.

Copyright: $(\odot 2021$ by the authors. Licensee MDPI, Basel, Switzerland. This article is an open access article distributed under the terms and conditions of the Creative Commons Attribution (CC BY) license (https:// creativecommons.org/licenses/by/ $4.0 /)$.

\begin{abstract}
Demand side response is becoming an increasingly significant issue for reliable power systems' operation. Therefore, it is desirable to ensure high effectiveness of such programs, including electricity tariffs. The purpose of the study is developing a method for analysing electricity tariff's effectiveness in terms of demand side response purposes based on statistical data concerning tariffs' use by the consumers and price elasticity of their electricity demand. A case-study analysis is presented for residential electricity consumers, shifting the settlement and consequently the profile of electricity use from a flat to a time-of-use tariff, based on the comparison of the considered tariff groups. Additionally, a correlation analysis is suggested to verify tariffs' influence of the power system's peak load based on residential electricity tariffs in Poland. The presented analysis proves that large residential consumers aggregated by tariff incentives may have a significant impact on the power system's load and this impact changes substantially for particular hours of a day or season. Such efficiency assessment may be used by both energy suppliers to optimize their market purchases and by distribution system operators in order to ensure adequate generation during peak load periods.
\end{abstract}

Keywords: demand side response; residential consumers; correlation; price elasticity; electricity demand; load profile

\section{Introduction}

The power system in Poland is constantly developing in accordance with provisions of the European directives [1,2], aiming to create uniform energy market conditions in the Member States of the European Union [3]. However, according to [4,5], in 2018, approximately $77 \%$ of energy consumed in Poland was produced from hard coal (48\%) and lignite $(29 \%)$, which causes significant pollution to the environment. Only about $75 \%$ of hard coal is mined domestically, and the remaining $25 \%$ is imported from various other countries, but mainly from Russia. The long term remedy lies in increasing the share of renewable energy sources in energy consumption, which amounted to $13 \%$ of electricity use in 2018, while it is expected to reach $15 \%$ of the final energy consumption in 2020. According to [6], the share of renewable capacity mix in Poland in 2025 will reach $40 \%$ in 2025 and is going to increase in 2030 by $10 \%$ compared to 2025 . Intensification of renewable energy sources' use for covering electricity demand prompts the research into flexibility services to grant security of the power system. Ensuring power system's security and reliability of electricity supply is a key priority of network operators, as serious problems with generation adequacy could be observed, e.g., in 2015 [7,8]. Among other measures [9], demand side response (DSR) is becoming increasingly important for supporting the effective and safe operation of the power system. The growing importance of DSR programs is related to the growing peak electricity demand and difficulties of regional power systems in covering this demand. Problems with ensuring reliable electricity supply 
are most often visible during peak demand of the winter or summer period, associated with extreme outdoor temperatures. Moreover, a reason for the increasing importance of DSR is the expansion of renewable energy sources that cover the power demand at the expense of large power plants using conventional fuels, which limits the availability of the conventional resources, the elasticity of which was used traditionally as a measure for balancing the operation of the power system.

In Poland, electricity is traded in the wholesale energy market that enables hourly price determination in result of long-term, day-ahead, and intraday transactions completed by a balancing mechanism according to market rules including selling electricity by traditional power generation utilities as well as renewable sources and purchasing the energy by large energy consumers as well as electricity suppliers [10-12]. Electricity price in the wholesale market incorporates the $\mathrm{CO}_{2}$ emissions costs, and the market rules enable introducing tariff demand response, remuneration for connecting renewable resources to the network, or implementing energy efficiency measures. Considering the coal-based electricity generation, the electricity prices are rising constantly and are among the highest in the European Union [13], making electricity consumption a strong financial burden for both industries and smaller electricity consumers.

Therefore, application of DSR programs may not only enhance reliability of the power system, but may also enable savings in terms of energy costs for the final consumer. Two classes of demand side response programs may be distinguished, i.e., price- and incentivebased $[14,15]$. Both types of demand response programs enable rewarding customers for reducing loads during peak power system load periods, provided such reduction is performed effectively. Organizers of incentive-based programs additionally inform participants about the expected time of load reduction, creating solutions to be used for operating power system control. Such programs, including services of interruptible loads organised by Polish transmission system operator (TSO), resulted in the load reduction of $500 \mathrm{MW}$ in 2018 [16]. What is more, the new measure allowing introduction of demand response services in the capacity market is currently introduced in Poland, which is intended to operate since 2021 and will allow for participation in DSR of many more industrial enterprises $[17,18]$.

Among various price-based DSR programs, such as critical peak pricing or real-time pricing $[19,20]$, only zonal time-of-use (TOU) electricity tariffs are available for various groups of consumers in Poland, and they are organised both by electricity suppliers and distribution system operators. Such programs create a stable incentive system of constant impact on the consumers as a result of electricity price differentiation during particular hours of the day [21,22] and enable increasing the flexibility of the energy systems [23]. As smaller energy consumers may not participate in the wholesale energy market, they may only seek financial savings within electricity purchase by choosing the most competitive energy supplier or by deciding on the settlement according to pre-set flat or time-of-use electricity tariffs. Tariff programs used in Poland are described in Section 2.1, as they are the basis of the presented analysis.

It should also be noted that price elasticity of electricity demand of particular consumers has a significant impact on the potential of DSR programs. Thus, the price elasticity of electricity consumers was determined in numerous studies, but its values for residential consumers were established as constant for a given time period, usually for a selected year [24-30]. However, as a consequence of very complex process of electricity consumption modelling, which should include various external variables, it is often believed that in order to ensure high reliability of the modelled DSR programs, price elasticity of demand should combine both self elasticity and cross elasticity of electricity demand, which vary over time for different seasons, months, or days. [31-33]. Regardless of the adopted assumptions regarding the price elasticity of demand, its values may be used further for designing new DSR programs and for assessing the effectiveness and impact of already implemented methods with greater focus on power system peak demand periods. 
What is more, households constitute a specific group of electricity consumers, and due to their repetitive character, it is possible to use the potential of aggregated residential consumers to control the load in the domestic power system, especially in case of smart grid networks. Numerous challenges related to application of such programs have been identified, including adjustment of residential DSR programs to the energy market's price variation, significant initial investments in the smart meters and necessary infrastructure, coordination and communication between the power system control centres, consumers who may shift their electricity consumption, and ultimately possible peak load shifting into other undesirable periods [34,35].

A useful tool for assessing the relationship between electricity consumption in various parts of the power system or for various consumers' types may be correlation analysis. Correlation coefficients are often used for load prediction or load profiles' determination [36-38]. Correlation may also be used to manage electrical properties of the grid, such as voltage levels, by distribution system operators (DSOs) [39], or to assess the impact of external factors such as income, age, and population density of customers on residential electricity consumption [40]. Correlation coefficients may also be used to assess the potential of demand side response programs to optimize development plans of generating units [41].

As the appropriately designed DSR programs are among the measures that increase the elasticity of customers needed to increase the power system operation safety in the view of the growing share of renewable energy sources with intermittent generation cycle in covering the demand in Poland, a task of devising the methodology able to verify the efficiency of TOU DSR programs in providing the elasticity of demand and to indicate the ways of its improvement has been undertaken. It was a motivation to prepare the presented study including in detail:

- $\quad$ presentation of the widespread use of price-based DSR programs in Poland,

- analysis of the effectiveness TOU tariffs, used as price-based demand response programs, influence on residential consumers consumption profile change considered annually, seasonally, and in the period of possible peak power consumption in the power system, resulting from their price elasticity of demand, based on the comparison of existing flat and TOU tariff groups,

- verification of the potential threats of residential tariff programs in terms of their peak load impact on the power system load curve through correlation analysis of the customers' and power system's load profiles.

Section 2 describes materials and data used for the analysis, which are statistical data concerning electricity tariffs and residential consumers in Poland as well as their load profiles. Section 3 presents the proposed method for assessment of zonal tariffs' influence on the power system load, while in Section 4, the results of a case-study analysis of TOU residential tariff's influence of Polish power system including peak power demand periods are described. Section 5 contains the results of load profiles' correlation analysis. All the results are discussed in Section 6, and final conclusions are presented in Section 7.

\section{Materials and Data for the Analysis}

\subsection{Price-Based Demand Side Response Programs in Poland}

Price-based demand side response programs are implemented in Poland through various time-of-use tariffs offered to different customers' groups. Zonal tariffs play an important role in load management in Poland, considering the share of electricity supplied within such tariffs in relation to all distributed energy, which amounted to $64 \%$ in 2016 and $65 \%$ in 2017. These values prove a significant impact of tariff DSR on the power system load. Demand side response programs in the form of TOU tariffs are used both by electricity suppliers and distribution system operators. A system of zonal tariffs is used in Poland at each distribution voltage level. Flat tariffs as well as two- or three-zone tariffs are offered at the $110 \mathrm{kV}$ voltage level and for medium and low voltages for commercial and industrial customers. Flat and TOU tariffs are available also for household consumers. A summary of 
zonal tariffs' use is presented in Figure 1 through the amount of electricity supplied within such tariffs for different tariff groups in Poland in 2016 and 2017 based on data from [42,43]. The levels of TOU tariffs' use for particular tariff groups are as follows:

- over $85 \%$ for A tariff groups for customers connected to the $110 \mathrm{kV}$ grid in 2017 (annual volume of approx. 25,000 GWh) and for B tariff groups for customers connected at the medium voltage level from 6 to $30 \mathrm{kV}$ (annual volume 51,000 GWh);

- over $46 \%$ in the $\mathrm{C} 2$ tariff group, for commercial and industrial consumers connected to the low voltage (LV) network of $0.4 \mathrm{kV}$, with contracted power over $40 \mathrm{~kW}$ (annual volume of approx. $9800 \mathrm{GWh}$ );

- over $55 \%$ in the $\mathrm{C} 1$ tariff group, for commercial and industrial customers connected to the $\mathrm{LV}$ network of $0.4 \mathrm{kV}$ with contracted power up to $40 \mathrm{~kW}$ (annual volume of 14,000 GWh);

- approximately $22 \%$ in the $\mathrm{G}$ tariff group for households with an annual volume of electricity supply of $31,000 \mathrm{GWh}$.

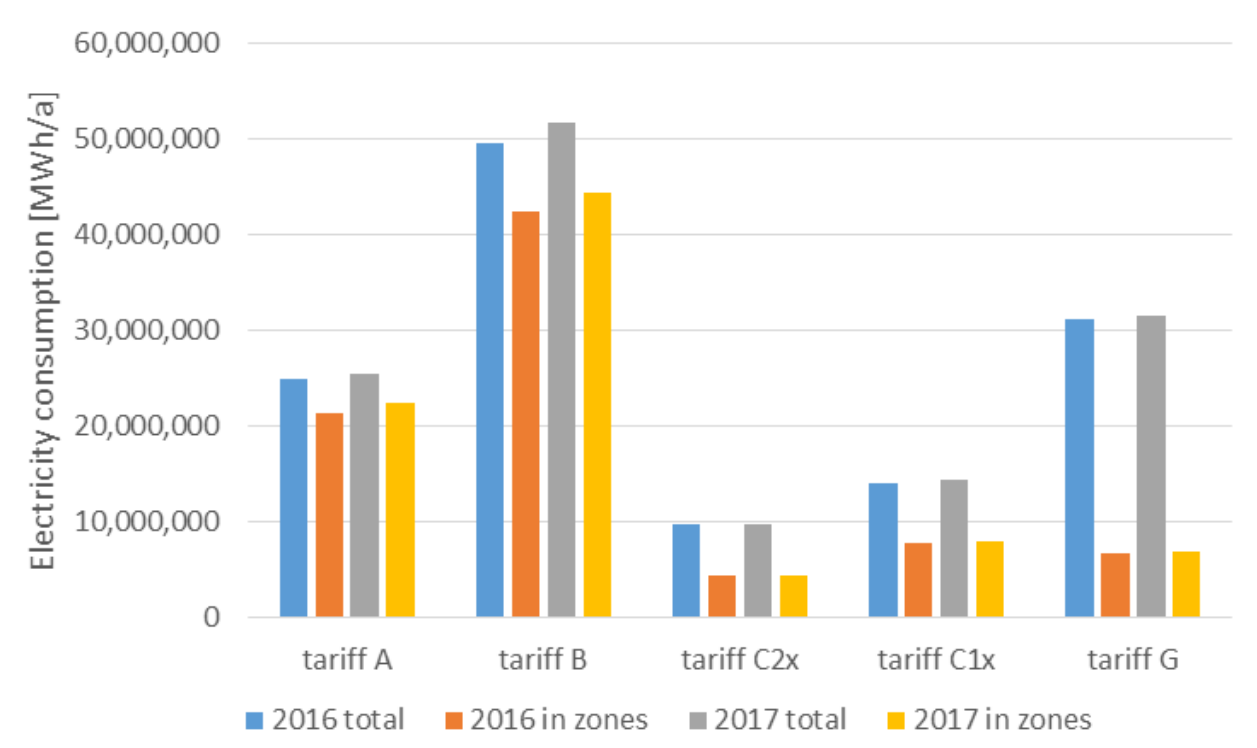

Figure 1. Electricity supplied within zonal tariffs and total electricity consumption for particular tariff groups in 2016 and 2017 in Poland based on [42,43].

It may be noticed that zonal settlements prevail at higher voltage levels for groups A and $\mathrm{B}$, reaching even $85 \%$ of total electricity supply in these groups. For low voltage industrial and commercial customers, TOU tariffs' use drops to $45-56 \%$, while for residential consumers, it reaches only $21-22 \%$. Therefore, the potential for future TOU tariffs' use by household consumers seems to be significant, and development of demand side response programs for this group may have a positive impact on shaping the power system load curve during peak load periods. Thus, it is important first to analyse the impact of the currently used zonal tariffs for households on the peak load of the power system.

\subsection{Use of Zonal Electricity Tariffs as a Tool for Residential Consumers Demand Response}

Residential consumers in Poland are settled for electricity consumption on the basis of electricity tariffs set by energy supplier and distribution system operator. Household consumers can choose the following tariffs:

- G11 tariff-flat tariff, with a uniform electricity price applied for all hours of a day;

- G12 tariff-two-zone time-of-use tariff for which the peak zone (the zone of higher rates) lasts between 6:00-13:00 and 15:00-22:00 on all days of the week, and the off-peak zone (the zone of lower rates) applies to all the remaining hours; 
- G12w tariff-two-zone TOU tariff, for which the peak zone applies from Monday to Friday between 6:00 and 21:00, while the off-peak zone applies at nights and during weekends.

Additionally, for two DSOs in Poland, it is possible to choose G13 three-zone TOU tariff, divided into morning peak zone, afternoon peak zone, and off-peak zone, but its use is insignificantly low. The amount of energy consumed in the $G$ tariff group within TOU tariffs reaches about $7000 \mathrm{GWh}$, which is over $20 \%$ of all energy supplied to residential consumers $[37,38]$. Shares of annual energy consumption by residential consumers using G12 and G12w settlement and average annual consumptions of individual households in these tariffs in 2016 and 2017 are shown in Figure 2.

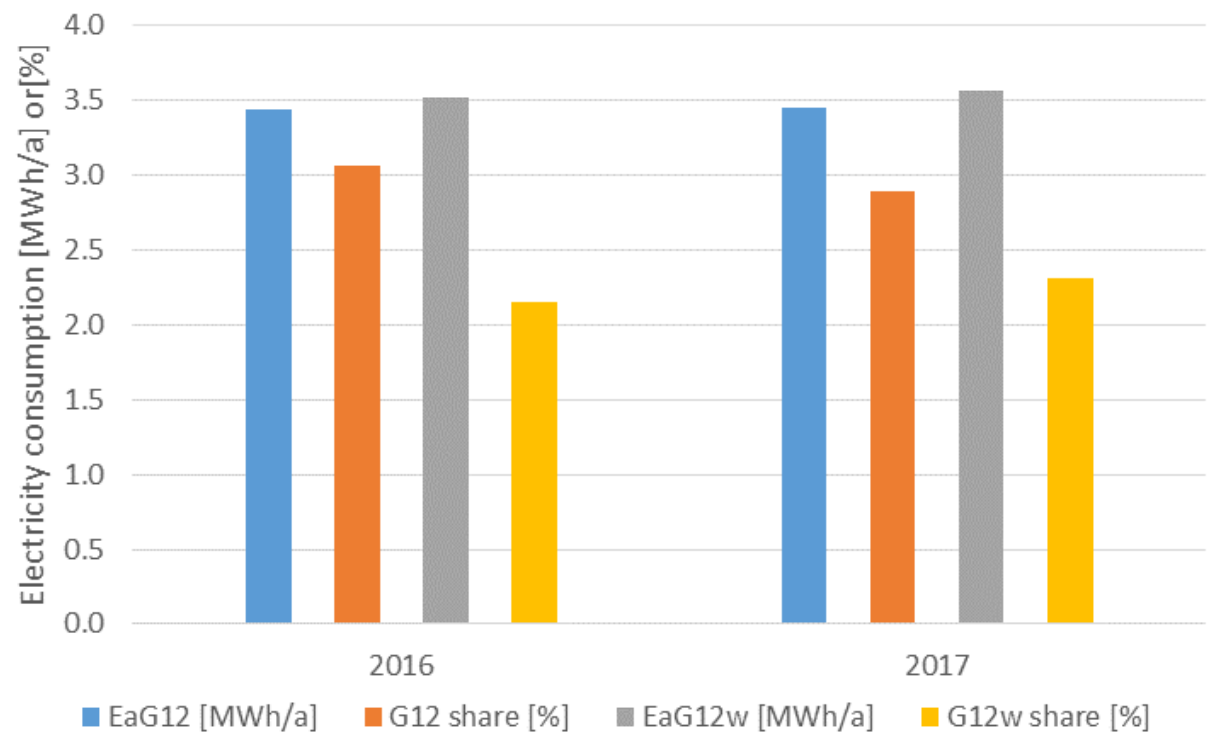

Figure 2. Shares of G12 and G12w tariffs in residential consumers' annual electricity consumption in Poland in 2016 and 2017 and individual consumer's average consumption for these tariffs [42,43].

Average annual energy consumption for customers settled according to the G12 tariff reaches almost 3.5 MWh and is twice as high as the average energy consumption of a consumer settled in accordance with G11 flat tariff. Demand management may be interesting and effective for customers with load reduction capabilities, which extend along with individual energy consumption increase. The larger consumers within the households group benefit the most from participation in the DSR program, and they may be interested in increasing their benefits if they are provided with alternative zonal tariff offers. Such consumers often decide to change the tariff from the flat G11 to the TOU G12 as the consequence of acquiring important electricity receivers used in the off-peak zone such as storage heaters or an electric vehicles mainly loaded at night.

\subsection{Standard Load Profiles for Household Electricity Consumers}

Households consume annually about a quarter of the total energy used in the power system, and they influence the load curve of the power system to a large extent, especially during the evenings. Currently, the vast majority of households in Poland are not equipped with smart metering systems that would enable hourly billing of the energy they consume. Introduction of the electricity market made it necessary to settle the wholesale energy purchases of electricity suppliers in hourly periods. Thus, hourly energy consumption of residential consumers, needed for the settlement processes on the market, is determined by standard load profiles for individual tariff groups, according to which the customers are settled. Moreover, consumers' load profiles may be used by electricity suppliers for energy purchase planning or by DSOs for implementing demand side response techniques to predict overloading in the elements of power infrastructure. 
Standard load profiles for individual tariffs are published by regional distribution system operators (DSOs) for particular years in their Grid Codes on the basis of energy consumption measurements for groups of typical customers provided with smart metering systems. According to the Energy Law Act [44], DSOs are required to provide information on planned and actual electricity consumption, specified using the above-mentioned profiles in specific accounting periods. The standard load profile is a set of data on the average electricity consumption by a particular tariff group in particular hours of a day for the whole year and applies to the consumers who:

- $\quad$ are not provided with metering and billing devices enabling registration electricity consumption profile,

- have similar characteristics of electricity consumption, and

- are located in the area of operation of a given DSO.

The profiles concerning residential customers are data sets for particular Gxx tariffs containing the values of relative energy consumption HGxxi in the $i^{\text {th }}$ hours of the year of a representative customer expressed in relation to their annual consumption $E_{a}$. They are presented as relative values that sum up to 1000 in the annual period. Standard load profiles should reflect the daily and seasonal variability of the customers' consumption as accurately as possible and should be similar to load profiles that could be obtained by aggregating smart meters' measurement results.

The variability of the daily load profiles for the G11 flat tariff and the G12 and G12w TOU tariffs available for households is shown in Figure 3 for an exemplary summer day and in Figure 4 for an exemplary winter day of 2017. For the purpose of visualization, the hourly data is connected with solid lines to present a constant load profile.

The shape of the daily load profiles for summer and winter days differs significantly. In winter, there is a clear distinction between peak and off-peak periods. For the G12 profiles, the afternoon two-hour off-peak period may be easily observed, as it results in the considerable increase in energy demand. The G12w profile for weekdays is similar to the G11 profile, because it does not contain an off-peak zone during a day, and therefore the influence on the power system load curve is similar for these tariffs. Hence, under the G12w tariff, the increased consumption takes place during the weekends; its profile is not related to the power system peak load and its influence is negligible for that period, thus further analyses will only be performed for the G12 profile.

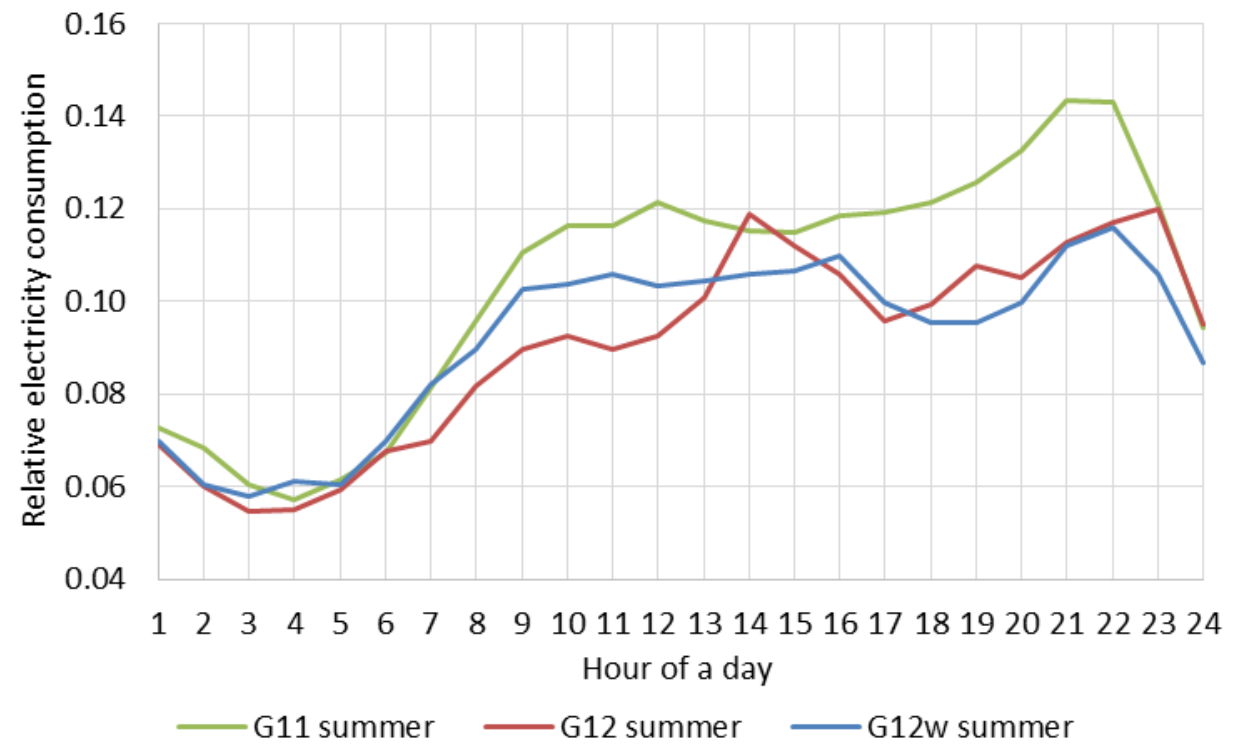

Figure 3. Load profiles for G11, G12, and G12w tariffs for a summer day of 2017 for Enea Operator DSO distribution area. 


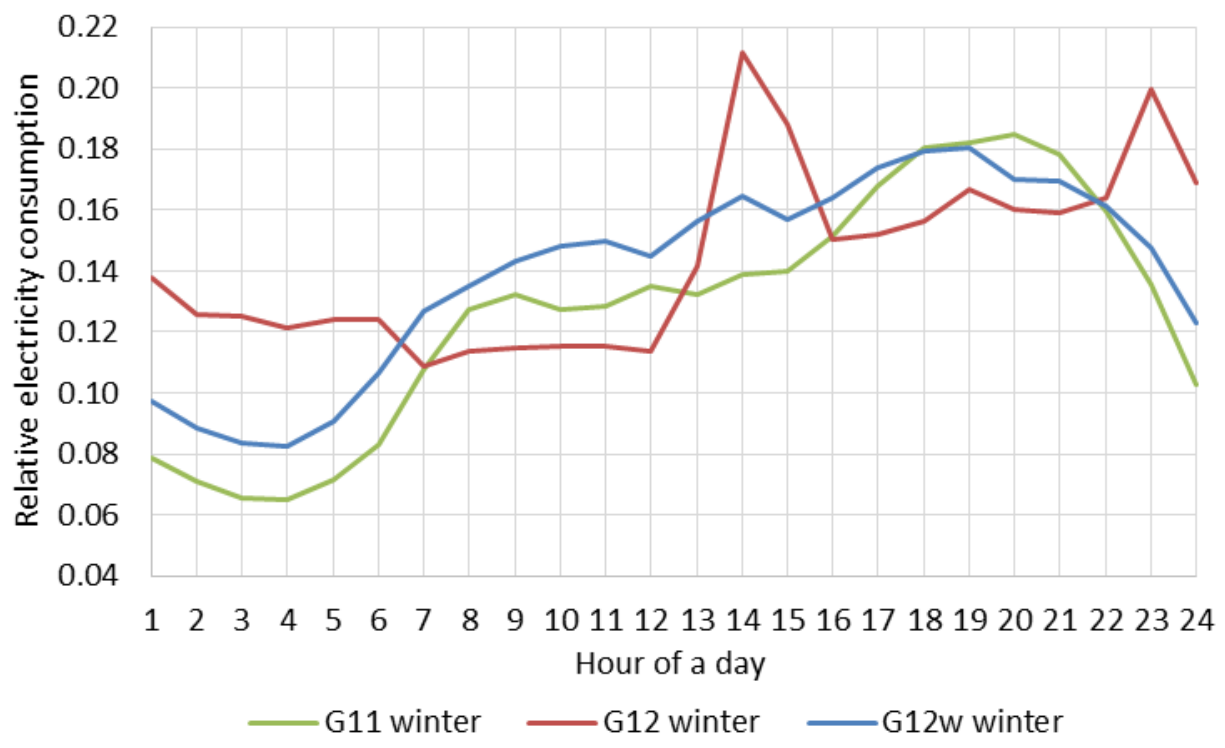

Figure 4. Load profiles for G11, G12, and G12w tariffs for a winter day of 2017 for Enea Operator DSO distribution area.

For the G11 and G12 profiles, there is a noticeable difference in the electricity consumption for different zones, as well as different seasons. Daily consumption values for a statistical electricity consumer in G11 and G12 tariffs are illustrated in Figure 5 for G12 average annual consumption in 2017 and corresponding price elasticity of demand used in further calculations, as presented in Formula (14). Due to the use of the G12 tariff for the purposes of partial or additional space heating, daily summer consumption accounts for $2 / 3$ of winter consumption, while there are only slight differences in daily summer consumptions in relation to the G11 tariff. Data presented in Figure 5 reflects the static relationship of the load profiles of the consumers within G11 and G12 tariff groups with average electricity consumption in a year, which is analysed within this paper.

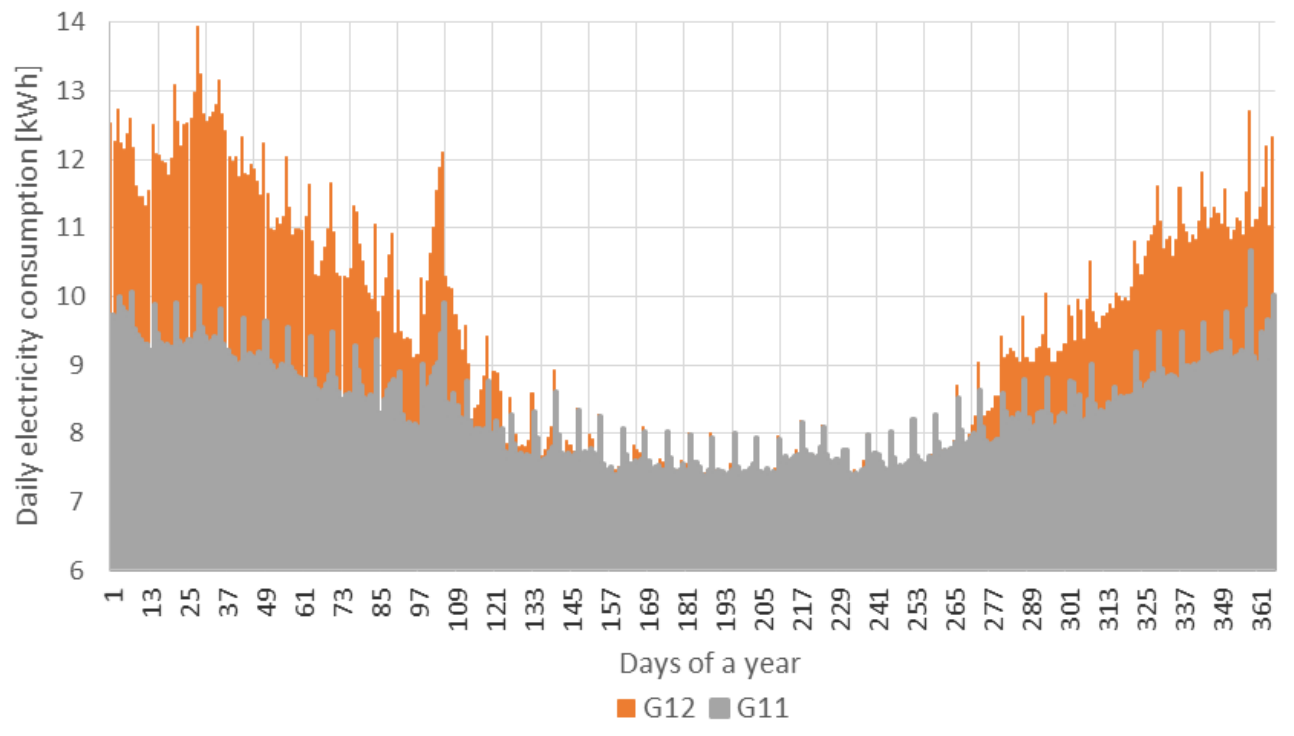

Figure 5. Daily electricity consumption for statistical consumers in G11 and G12 tariffs with annual consumption and price elasticity of demand in 2017 presented in Formula (14). 


\subsection{Input Data Used for the Analysis}

In detail, the following input data is used for designing the proposed methodology and the subsequent case-study and correlation analyses, which is also described further in the following sections:

- $\quad$ share of TOU tariff's use for particular tariff groups in Poland in contrast to the use of flat tariffs, presented in Figures 1 and 2, particularly for residential consumers based on [37,38];

- average annual electricity consumption values for G12 tariff's customers marked as $E_{a G 12}$ for the years 2016 and 2017 presented with (13) and (14) based on [42,43];

- average annual price elasticity of demand values for the considered consumers presented with (13) and (14) based on [27];

- $\quad$ standard load profiles for the G11 and G12 tariff presented by a chosen DSO for 2016 and 2017 consisting of values of relative energy consumption HGxxi in the $i^{\text {th }}$ hours of the year of a representative customer expressed in relation to their annual consumption $E_{a}$ which are provided in Tables S1 and S2 in the Supplementary Materials [45];

- electricity prices for the analysed tariff groups in the considered area, including the energy prices, and variable and fixed distribution fees for years 2016 and 2017, calculated later with (1) and (2) [46-49]; and

- load profile of the Polish power system for the years 2016 and 2017 provided by the Polish transmission system operator [50].

\section{Method for Zonal Tariffs' Influence Assessment}

Zonal tariffs may influence the customers' consumption profile by differentiating the costs of using electricity depending on the time of a day. These costs include the purchase price of energy from a supplier and the delivery costs of the purchased energy to the final consumer, invoiced by a local distribution system operator. The costs of energy consumption by the final consumer may be divided into variable and fixed fees. The variable cost includes the price of energy, a variable distribution rate, and a quality fee for maintaining reserves in the power system, as well as fees related to covering the costs of developing renewable and cogeneration energy sources. Fixed fees comprise contracted capacity and a subscription fee. Among the electricity costs, the variable distribution rate and the price of energy are subject to differentiation depending on the period of energy consumption during the day. Fixed rates affect the overall cost for electricity use, but their impact decreases along with the increase in the amount of energy used.

Choice of the settlement method between the flat or time-of-use tariff with different electricity price levels depends on the consumers. For customers choosing TOU tariffs, with different levels of energy prices and rates of distribution fees during the day, it is important to calculate annual billing costs for electricity consumption in individual zones and assess the possible profits from using such tariff in comparison to a flat settlement.

In tariff settlements, valid for annual periods, the settlement prices for electricity consumption in particular time zones may be determined using the following equation:

$$
P_{i}=C_{i e}+\sum_{i} S_{i}+\frac{\sum_{k} O_{s t k}}{E_{a}}
$$

where: $C_{i e}$ - energy prices in the $i^{\text {th }}$ tariff zone [PLN/kWh], $S_{i}$-distribution and transmission fees in the $i^{\text {th }}$ tariff zone [PLN/kWh], $\Sigma_{k} O_{s t k}$-sum of $k$ fixed charges applicable in the considered tariff settlement [PLN], and $E_{a}$-annual energy consumption [kWh]. In the case of a flat tariff, $i=1$, as there is one settlement price for the entire period of using the tariff.

Distribution system operators determine the number of zones as well as their duration with the start and end time for differentiated distribution fees, and electricity suppliers may adapt their commercial offers accordingly and compete for the customers in terms of energy prices. 
The basic reason for choosing zonal settlement in TOU tariffs is the reduction of costs for using electricity during the year by lowering the average settlement price in the zonal tariff in relation to the settlement price in the flat tariff. The average settlement price $P_{a v}$ in TOU tariff may be determined as follows:

$$
P_{a v}=\frac{\sum_{n}\left(P_{r i} \cdot E_{i}\right)}{\sum_{n} E_{i}}
$$

where $P_{r i}$ - settlement prices for energy consumption in particular zones and $E_{i}$-volumes of energy consumed in particular zones.

Lowering the average unit price for electricity consumption is a measurable effect for customers using zonal settlements. An important aspect of reaching specific effects of the zonal tariffs is the customer's reaction to a price change, which is a change in energy consumption, assessed by the price elasticity of demand of a given consumer group. The group of consumers deciding to change their settlement from the flat tariff to the zonal tariff is characterized by the following average annual price elasticity of demand:

$$
\varepsilon=\frac{\Delta E_{a(S-1)}}{E_{a 1}} / \frac{\Delta P_{(S-1)}}{P_{1}}=\frac{\Delta E_{a(S-1)}}{E_{a S}-\Delta E_{a(S-1)}} / \frac{P_{a v}-P_{1}}{P_{1}}
$$

where: $E_{a 1}$-annual energy consumption in a flat tariff, $E_{a S}$-annual energy consumption in a tariff with zonal settlement prices, $\Delta E_{a(S-1)}$-difference in annual energy consumption between flat and TOU settlement, $P_{1}$-settlement price in a flat tariff, $\Delta P_{(S-1)}$-difference in electricity price between flat and average annual TOU settlement, and $P_{a v}$-average annual TOU settlement price defined by (2).

In the considered analysis, the value of price elasticity of demand reflects the differences in consumption profile between G11 and G12 groups of consumers. Consumers from G12 group show a higher electricity consumption in off-peak zone and a lower consumption in peak zone or combine both effects, resulting in lower energy bills comparing to the G11 settlement. Such patterns of electricity use exposing their elasticity should be sustained unless they lose the expected profits. The price elasticity of demand has negative values, which implies that lowering the settlement price is related to a higher energy demand.

Knowing the average values of prices and energy demand for a given tariff group for the year, it is possible to determine the annual average price elasticity of this group [27]. One of the fundamental measures of zonal DSR programs' effectiveness may be the higher energy consumption for a TOU tariff in comparison to energy consumption in a flat settlement. Based on equation (3), it is possible to determine the difference in average electricity consumption during the year by a customer settled in zones comparing to the consumption in a flat tariff, as follows:

$$
\Delta E_{a(S-1)}=\frac{\varepsilon \cdot E_{a S} \cdot\left(P_{a v}-P_{1}\right)}{\varepsilon \cdot P_{a v}+P_{1} \cdot(1-\varepsilon)}
$$

The presented formula enables the assessment of zonal tariffs' effectiveness, if statistical data concerning the average electricity consumption in individual zonal tariffs, average energy prices and distribution fees in these tariffs, and price elasticity values of customers' demand are available. In the presented analysis, the assessment is based on the comparison of average annual load profiles of the existing G11 and G12 electricity consumers.

The difference in energy consumption related to the settlement change from flat to TOU tariff may be divided into change in energy consumption in peak periods $\Delta E_{a p(S-1)}$ and in off-peak periods $\Delta E_{a o(S-1)}$. If the consumption change in the peak zone $\Delta E_{a p(S-1)}$ is negative, it improves the effectiveness of zonal tariff's impact according to the equation:

$$
\Delta E_{a(S-1)}=\Delta E_{a o(S-1)}-\Delta E_{a p(S-1)}
$$


The zonal consumption differences, presented as percentage of total energy consumption in the flat tariff, indicate to what extent the goals in terms of reducing energy consumption in peak periods and its increase in off-peak periods are fulfilled in the zonal tariff in relation to the flat tariff, and they may be determined as follows:

$$
\begin{aligned}
& \Delta E_{a 0 \%}=\frac{100 \cdot \Delta E_{a o(S-1)}}{\Delta E_{a 1}} \\
& \Delta E_{a p \%}=\frac{100 \cdot \Delta E_{a p(S-1)}}{\Delta E_{a 1}}
\end{aligned}
$$

If the positive values of consumption differences in the off-peak zone and the negative values in the peak zone are equal $\Delta E_{a o(S-1)}=-\Delta E_{a p(S-1)}$, then no increase in the total consumption can be observed when comparing the flat and TOU tariff. The benefits, however, result from shifting the consumption from the peak to the off-peak zone. In such a case, the two-zone tariff is effective, and zonal consumption differences may be calculated for individual peak and off-peak periods.

Using (4), it is possible to determine the annual consumption $E_{a G 11}$ of these customers before changing their settlement from flat to TOU tariff based on the average annual consumption $E_{a G 12}$ of the G12 tariff customers and their price elasticity of demand. Determining the changes in energy consumption in particular zones requires comparing the customer's load profiles for both the G11 and the G12 tariff. Annual load profiles of G11 and G12 tariffs with known values of annual electricity consumption $E_{a G 11}$ and $E_{a G 12}$ enable determination of such increments for particular hours $\Delta E_{h}$ according to the formula:

$$
E_{h}=E_{h G 12}-E_{h G 11}=E_{a G 12} \cdot H_{h G 12}-E_{a G 11} \cdot H_{h G 11}
$$

where: $E_{h G 12}, E_{h G 11}$-hourly consumption in G11 or G12 tariff, $E_{a G 12}, E_{a G 11}$-annual electricity consumption in G11 or G12 tariff, and $H_{h G 12}, H_{h G 11}$-relative hourly consumption in relation to the annual consumption given in the standard load profiles.

The cumulative increments in a given period of the day covering hours from $i$ to $j$ can be calculated by summing up the hourly increments:

$$
\Delta E_{i-j}=\sum_{i}^{j} \Delta E_{h}
$$

Daily consumption differences are subject to stochastic variations occurring as a result of changes in climatic or social conditions of the tariff users. Their individual overlapping with the stochastic threats to the generation adequacy of the power system components is however very unlikely. In the Polish power system, the reserves to ensure generation adequacy are determined for monthly peak loads calculated as the average peak load for the weekdays in the considered month. The impact of higher consumption related to the tariff settlement change in the case of households can be therefore determined as average for days or hours in the periods of significant risk of peak loads of the power system.

In general, the risk resulting from the profile change can be presented as a certain average level of consumption difference in the analysed zones as a result of similar external conditions in certain periods, e.g., summer or winter season. It may be determined in a form of higher electricity consumption in a given TOU zone in relation to the consumption in the same zone of the G11 tariff. For the period covering $d z$ days and hours from $i$ to $j$ on each day, the relative threats (12) resulting from absolute consumption differences (10) in relation to the flat tariff consumption level (11) can be determined as follows:

$$
\begin{gathered}
E_{z(G 12-G 11)}=\sum_{d z} \Delta E_{i-j} \\
E_{z G 11}=E_{a G 11} \sum_{d z} \sum_{i}^{j} H_{h G 11}
\end{gathered}
$$




$$
\Delta E_{z G 12 \%}=\frac{100 \cdot \Delta E_{z(G 12-G 11)}}{E_{z G 11}}
$$

where: $z$-analysed period, $d z$-number of days in the period, and $i$ to $j$-hours $h$ of the analysed period duration within the day.

A substantial issue is also whether the effectiveness of consumption changes in particular zones, desired by the zonal tariff designers, corresponds with a positive or a negative impact on the peak load of the power system. Both of these issues are analysed in the following chapters using the example of tariff demand side response program available to households in Poland.

\section{Case Study Concerning G12 Tariff's Effectiveness Based on Statistical Data and Load Profiles}

Effectiveness of the price-based demand side response programs may be assessed in two aspects:

- changes in consumption in individual time zones, which is the goal of the program's organizers, i.e., energy suppliers and distribution system operators,

- impact of the tariff programs on the regional network's load and the peak load of the power system, which contributes to the improvement or deterioration of the operational security of this system, which may be a problem for transmission system operators.

Methods of assessing such effectiveness based on the available statistical data on electricity consumption and the daily and seasonal loads of the power system are presented below.

To evaluate the DSR programs' efficiency, statistical data on the average annual electricity consumption of G12 tariff customers are used, available for 2016 and 2017 as average values for all residential consumers [42,43]. The effectiveness analysis is based on the example of the G11 and G12 tariffs' load profiles of Enea Operator distribution system operator for 2016 and 2017 [45], described in general in Section 2.3. For the purpose of the analysis, the settlement prices $P$ were determined using the Equations (1) and (2) based on the tariff energy prices and distribution fees, considering the fixed fees for the selected distribution system operator and the dominant supplier in the considered area according to [46-49]. Average annual price elasticity values $\varepsilon_{a G 12}(4)$ were assumed for the selected energy supplier and DSO based on [27]. The collected data were used to determine the differences in annual electricity consumption due to different settlement prices in G11 and G12 tariffs (4), for the average annual electricity consumption of the G12 tariff customers in 2016 and 2017 for selected time scopes of their load profiles.

The values of the annual energy consumption by the G12 tariff customers $E_{a G 12}$ and established corresponding consumption value in G11 tariff $E_{a G 11}$ allow for mapping hourly consumption patterns in the form of hourly load profiles. Then, it is possible to assess the differences in consumption for individual periods of the G12 tariff in relation to the G11 profile, using the Equations (8)-(12).

In order to assess the efficiency of the zonal tariff comparing to the flat tariff, differences in consumption in the G12 tariff in relation to the G11 tariff were determined for three time scopes:

- peak zone hours and off-peak zone hours throughout the whole year,

- peak zone hours and the off-peak zone hours in the summer season from 21 June to 20 September,

- peak zone hours and off-peak hours in the winter season from 21 December to 20 March.

In further calculations, electricity consumption values in G12 tariff group were assumed in accordance with the data for the whole country presented in Figure 2 and price elasticity values, adopted from [27], taking into account different average annual energy consumption in the considered case for the whole country and not only for one region for the years 2016 and 2017. The adopted values are based on the equations presented 
in [27], and they comply with the changes in elasticity values along with changes in annual electricity consumption as follows:

$$
\begin{aligned}
& E_{a 2016 \mathrm{G} 12}=3.434 \mathrm{MWh} ; \varepsilon_{a 2016}=-1.99 \\
& E_{a 2017 \mathrm{G} 12}=3.453 \mathrm{MWh} ; \varepsilon_{a 2017}=-1.87
\end{aligned}
$$

The resulting values of energy consumption differences in the G12 tariff zones comparing to the corresponding consumption periods in the G11 tariff are presented in Table 1 and in the Figure 6 for relative consumption differences.

Table 1. Energy consumption differences in peak and off-peak zones, in the G11 and G12 tariffs in

\begin{tabular}{|c|c|c|c|}
\hline & & 2016 & 2017 \\
\hline Annual price elasticity & $\varepsilon_{a}$ & -1.99 & -1.87 \\
\hline \multirow{2}{*}{$\begin{array}{l}\text { Difference in total annual } \\
\text { consumption }\end{array}$} & $\Delta E_{a G 12}[\mathrm{MWh}]$ & 0.381 & 0.397 \\
\hline & $\Delta E_{a \mathrm{G} 12}[\%]$ & 12.49 & 13.00 \\
\hline \multirow{2}{*}{$\begin{array}{l}\text { Annual differences in peak } \\
\text { consumption }\end{array}$} & $\Delta E_{a p G 12}[\mathrm{MWh}]$ & 0.19 & 0.17 \\
\hline & $\Delta E_{a p G 12[\%]}$ & 10.10 & 9.27 \\
\hline \multirow{2}{*}{$\begin{array}{l}\text { Annual differences in off-peak } \\
\text { consumption }\end{array}$} & $\Delta E_{a o G 12}[\mathrm{MWh}]$ & 0.50 & 0.54 \\
\hline & $\Delta E_{a 0 G 12}[\%]$ & 57.54 & 60.99 \\
\hline \multirow{2}{*}{$\begin{array}{l}\text { Differences in peak consumption } \\
\text { in summer }\end{array}$} & $\Delta E_{s p G 12}[\mathrm{MWh}]$ & -27.54 & -32.07 \\
\hline & $\Delta E_{s p G 12} / \Delta E_{s p G 11}[\%]$ & -5.89 & -6.85 \\
\hline \multirow{2}{*}{$\begin{array}{l}\text { Differences in off-peak } \\
\text { consumption in summer }\end{array}$} & $\Delta E_{s o G 12}[\mathrm{MWh}]$ & 26.64 & 27.90 \\
\hline & $\Delta E_{s o G 12} / \Delta E_{s o G 11}[\%]$ & 11.64 & 12.02 \\
\hline \multirow{2}{*}{$\begin{array}{l}\text { Differences in peak consumption } \\
\text { in winter }\end{array}$} & $\Delta E_{w p G 12}[\mathrm{MWh}]$ & 29.27 & 21.76 \\
\hline & $\Delta E_{w p G 12} / \Delta E_{w p G 11}[\%]$ & 5.07 & 3.82 \\
\hline \multirow{2}{*}{$\begin{array}{l}\text { Differences in off-peak } \\
\text { consumption in winter }\end{array}$} & $\Delta E_{w o G 12}[\mathrm{MWh}]$ & 194.33 & 201.11 \\
\hline & $\Delta E_{w o G 12} / \Delta E_{w o G 11}[\%]$ & 73.95 & 76.60 \\
\hline
\end{tabular}
2016 and 2017.

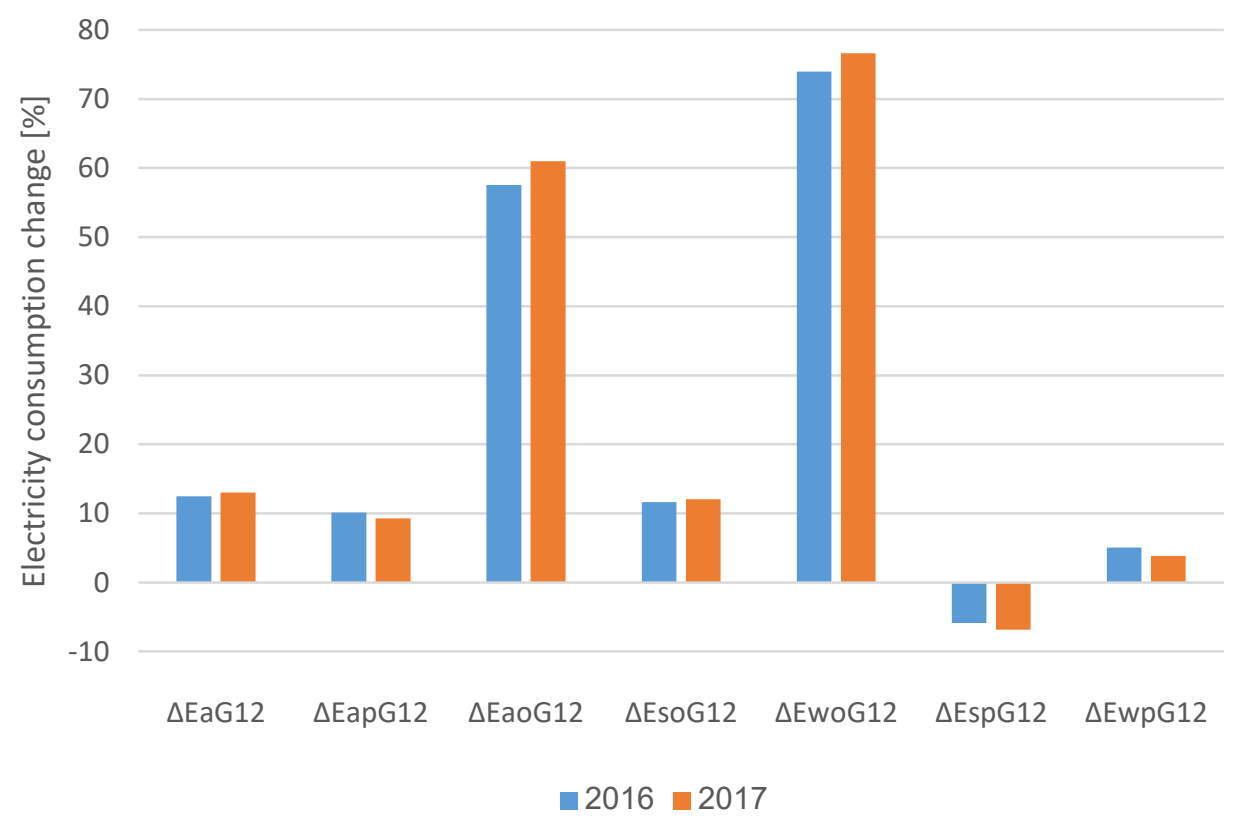

Figure 6. Energy consumption differences in peak and off-peak zones, in the G11 and G12 tariff in 2016 and 2017. 
Zonal tariffs' impact on the peak load of the power system should be analysed during the peak load periods, which are considered by the transmission system operator responsible for operational safety of the power system. According to Polish TSO, power system's peak load occurs in summer between 10:00 and 18:00 and in winter between 16:00 and 20:00 [15]. The risk of short-term consumption growth in the G12 tariff in these periods as the result of tariff change was determined based on Equations (8)-(12). The peak load was considered only for weekdays, as there are no threats of network overloading or insufficient generation adequacy during weekends and holidays.

It should be noted that the off-peak zone of the G12 tariff occurs at night, but also during the day between 13:00 and 15:00 in the afternoon. The coincidence of the higher consumption of customers in the G12 tariff in this period with the peak load of the power system is of crucial importance to the safety of the power system operation. Therefore, in summer, the average consumption increases on weekdays were analysed in three hourly intervals for the day 10:00-18:00, 12:00-16:00, and 13:00-15:00. The duration of analysed intervals was chosen with the aim to monitor the load increases in the period of the G12 tariff off-peak prices and in its vicinity. Similar calculations were carried out for winter but for individual hours of the peak period, i.e., 16:00-17:00, 17:00-18:00, 18:00-19:00, and 19:00-20:00, as in winter there is no coincidence of G12 tariff off-peak prices and the peak load of the power system.

The results of the performed calculations are presented in Table 2 for the summer days in various time intervals of the load peak (a) and for the winter days at particular peak load hours (b). Additionally, consumption differences in the G12 tariff are presented in Figure 7 for summer peak (a) and for winter peak (b).

Table 2. Average daily consumption differences on working days in the G12 tariff in relation to the G11 tariff in selected power system's peak load periods during summer (a) and winter (b) in 2016 and 2017.

\begin{tabular}{|c|c|c|c|c|c|c|c|c|}
\hline (a) & \multicolumn{4}{|c|}{ Summer 2016} & \multicolumn{4}{|c|}{ Summer 2017} \\
\hline Period & $10 h-18 h$ & $12 \mathrm{~h}-16 \mathrm{~h}$ & & $13 h-15 h$ & $10 h-18 h$ & & $6 \mathrm{~h}$ & $13 \mathrm{~h}-15 \mathrm{~h}$ \\
\hline$\Delta E_{s G 12}[\mathrm{kWh}]$ & 1.591 & 5.003 & & 6.611 & -1.214 & & & 4.711 \\
\hline$\Delta E_{s G 12}[\%]$ & 0.89 & 5.51 & & 15.00 & -0.68 & & & 10.65 \\
\hline (b) & \multicolumn{4}{|c|}{ Winter 2016} & \multicolumn{4}{|c|}{ Winter 2017} \\
\hline Period & $16 \mathrm{~h}$ & $17 \mathrm{~h}$ & $18 \mathrm{~h}$ & $19 \mathrm{~h}$ & $16 \mathrm{~h}$ & $17 \mathrm{~h}$ & $18 \mathrm{~h}$ & $19 \mathrm{~h}$ \\
\hline$\Delta E_{w G 12}[\mathrm{kWh}]$ & 2.395 & 0.328 & -0.387 & -0.144 & 2.908 & 0.692 & 0.004 & -0.056 \\
\hline$\Delta E_{w G 12}[\%]$ & 9.02 & 1.11 & -1.19 & -0.42 & 11.17 & 2.42 & 0.01 & -0.17 \\
\hline
\end{tabular}

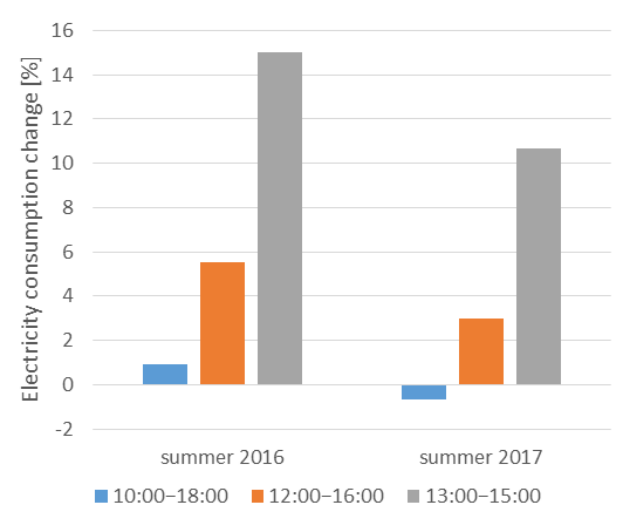

(a)

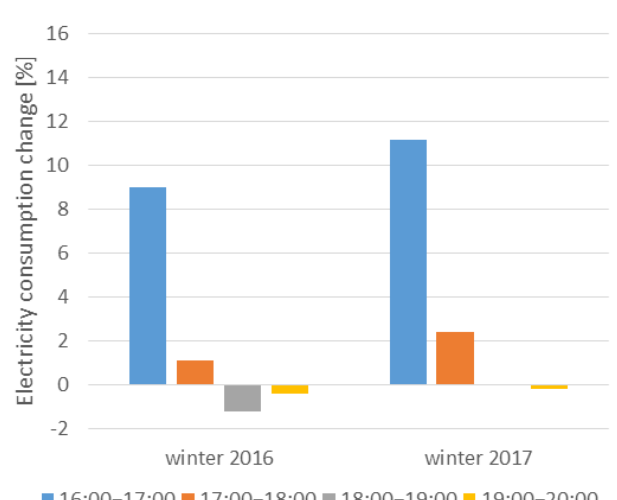

(b)

Figure 7. Average G12 consumption differences in peak hours of (a) summer and (b) winter. 
The presented consumption differences of the G12 tariff customers, compared to the G11 tariff, occurring in the peak load periods of the power system, may potentially lead to the increase of threats related to the safe operation of the system in these periods. However, the customers of the G12 group create the system load curve only to a limited extent related to their share in the power system load in relation to customers using other tariff groups also at different voltage levels. In order to confirm the negative impact of the load increments in the system caused by the increased load of customers using the G12 tariff, it may be useful to analyse the correlation of the hourly consumption profile in this tariff with the corresponding daily load profiles of the power system.

\section{Analysis of Load Profile Correlation}

Due to lack of detailed data on energy consumption in individual tariff groups in individual DSO areas, in order to assess the relation between household load profiles and the load of the domestic power system, correlation analysis of the annual standard load profiles of these customers for the area of one of the DSOs in Poland-Enea Operator Sp. z o.o with the power system's load profile was performed. This OSD was chosen as representative, because it covers both urban and rural areas, and its standard load profiles are the most carefully prepared and presented, which is another reason for adopting these profiles for the analysis as the most representative for residential consumers in Poland. For the purposes of the analysis, standard load profiles for 2016 and 2017 for G11 and G12 tariffs presented in Figures 3-5 were used along with the annual electricity consumption values in these tariff groups. Data on the load of the Polish power system were provided by the transmission system operator PSE S.A. for the years 2016-2017 [50].

To determine the correlation between the considered load profiles, the Pearson linear correlation coefficient was used, which is determined as follows:

$$
r_{x y}=\frac{\sum_{j=1}^{n}\left(x_{j}-\bar{x}\right)\left(y_{j}-\bar{y}\right)}{\sqrt{\sum_{j=1}^{n}\left(x_{j}-\bar{x}\right)^{2} \sum_{j=1}^{n}\left(y_{j}-\bar{y}\right)^{2}}}
$$

where $x_{j}$ are hourly consumers' load values in particular tariff groups, $y_{j}$ are hourly load values of the domestic power system, and $n$ is the number of analysed hours that depends on the considered period of analysis. The Pearson's coefficient ranges from -1 to +1 , with -1 representing complete negative correlation and +1 representing complete positive correlation. A value of 0 means no correlation.

The correlation coefficient values between the G11 and G12 tariff profiles and the load of the power system were determined for the following cases considering:

- hourly load values in the period of one year, taking into account $24 \mathrm{~h}$ for all days of the year;

- hourly load values in summer and in winter, taking into consideration 24-h load profiles on all days of the week;

- $\quad$ hourly load values for individual months of the year taking into account 24-h load profiles on all days of the week;

- hourly load values during the winter peak hours, i.e., 16:00-20:00 in the winter period (January, February, December); due to the risk of excessive load of the power system only on working days, weekends and holidays were excluded from the calculations; the correlation coefficient values are determined for the whole peak load period, as well as for individual hours of the peak period;

- $\quad$ hourly load values during the summer peak hours, i.e., 10:00-18:00 in the summer period (June, July, and August); in this case also, only weekdays were analysed to establish the influence of residential customers on the power system's peak load.

The results of correlation for the 24-h periods for both working days and holidays are important for the electricity suppliers, while the seasonal hourly correlation for the peak load periods are essential for network system operators in terms of demand side management goals and ensuring reliable operation of the power system. The results of 
the calculations in the form of year-round load correlation coefficients and correlation coefficients determined for summer and winter season as well as for individual months are presented in Table 3, while the correlation coefficients for the considered profiles in summer and winter peaks are presented in Tables 4 and 5. Additionally, to facilitate the observation of correlation coefficients' variability over time, their values for individual months are presented in Figure 8.

Table 3. Pearson coefficients for selected seasons and particular months considering 24-h load.

\begin{tabular}{ccccccc}
\hline Year & \multicolumn{2}{c}{ 2016 } & & \multicolumn{2}{c}{ 2017 } & \multicolumn{2}{c}{ Average } \\
\hline Tariff & G11 & G12 & G11 & G12 & G11 & G12 \\
\hline The whole year & 0.717 & 0.327 & 0.694 & 0.211 & 0.687 & 0.256 \\
Summer & 0.697 & 0.681 & 0.682 & 0.635 & 0.689 & 0.658 \\
Winter & 0.698 & 0.296 & 0.667 & 0.256 & 0.682 & 0.276 \\
\hline January & 0.759 & 0.264 & 0.732 & 0.240 & 0.730 & 0.255 \\
February & 0.656 & 0.369 & 0.706 & 0.244 & 0.654 & 0.289 \\
March & 0.662 & 0.417 & 0.584 & 0.300 & 0.612 & 0.370 \\
April & 0.617 & 0.544 & 0.630 & 0.480 & 0.607 & 0.506 \\
May & 0.674 & 0.641 & 0.652 & 0.587 & 0.651 & 0.616 \\
June & 0.700 & 0.690 & 0.697 & 0.655 & 0.689 & 0.672 \\
July & 0.721 & 0.716 & 0.698 & 0.665 & 0.697 & 0.683 \\
August & 0.713 & 0.673 & 0.714 & 0.621 & 0.687 & 0.632 \\
September & 0.692 & 0.571 & 0.710 & 0.508 & 0.694 & 0.520 \\
October & 0.722 & 0.481 & 0.706 & 0.421 & 0.686 & 0.439 \\
November & 0.639 & 0.308 & 0.604 & 0.275 & 0.598 & 0.291 \\
December & 0.717 & 0.327 & 0.694 & 0.211 & 0.687 & 0.256 \\
\hline
\end{tabular}

Table 4. Pearson correlation coefficient values for selected time intervals in summer.

\begin{tabular}{cccc}
\hline Year & $\mathbf{2 0 1 6}$ \\
\hline Time scope & $10: 00-18: 00$ & $12: 00-16: 00$ & $13: 00-15: 00$ \\
G11 & -0.3787 & -0.0815 & 0.0002 \\
G12 & 0.2260 & 0.0335 & 0.0288 \\
\hline Year & & $\mathbf{2 0 1 7}$ & \\
\hline Time scope & $10: 00-18: 00$ & $12: 00-16: 00$ & $13: 00-15: 00$ \\
G11 & -0.2996 & -0.3286 & -0.3025 \\
G12 & 0.0384 & -0.1109 & -0.1040 \\
\hline
\end{tabular}

Table 5. Pearson correlation coefficient values for selected time intervals in winter.

\begin{tabular}{cccccc}
\hline Year & \multicolumn{5}{c}{$\mathbf{2 0 1 6}$} \\
\hline Time scope & $16: 00-20: 00$ & $16: 00-17: 00$ & $17: 00-18: 00$ & $18: 00-19: 00$ & $19: 00-20: 00$ \\
G11 & 0.4775 & 0.3988 & 0.6683 & 0.5565 & 0.4156 \\
G12 & 0.3504 & 0.1623 & 0.4076 & 0.3306 & 0.0768 \\
\hline Year & & $\mathbf{2 0 1 7}$ & \\
\hline Time scope & $16: 00-20: 00$ & $16: 00-17: 00$ & $17: 00-18: 00$ & $18: 00-19: 00$ & $19: 00-20: 00$ \\
G11 & 0.4248 & 0.2772 & 0.5570 & 0.1849 & -0.1276 \\
G12 & 0.3444 & 0.1984 & 0.3810 & 0.2172 & -0.0243 \\
\hline
\end{tabular}




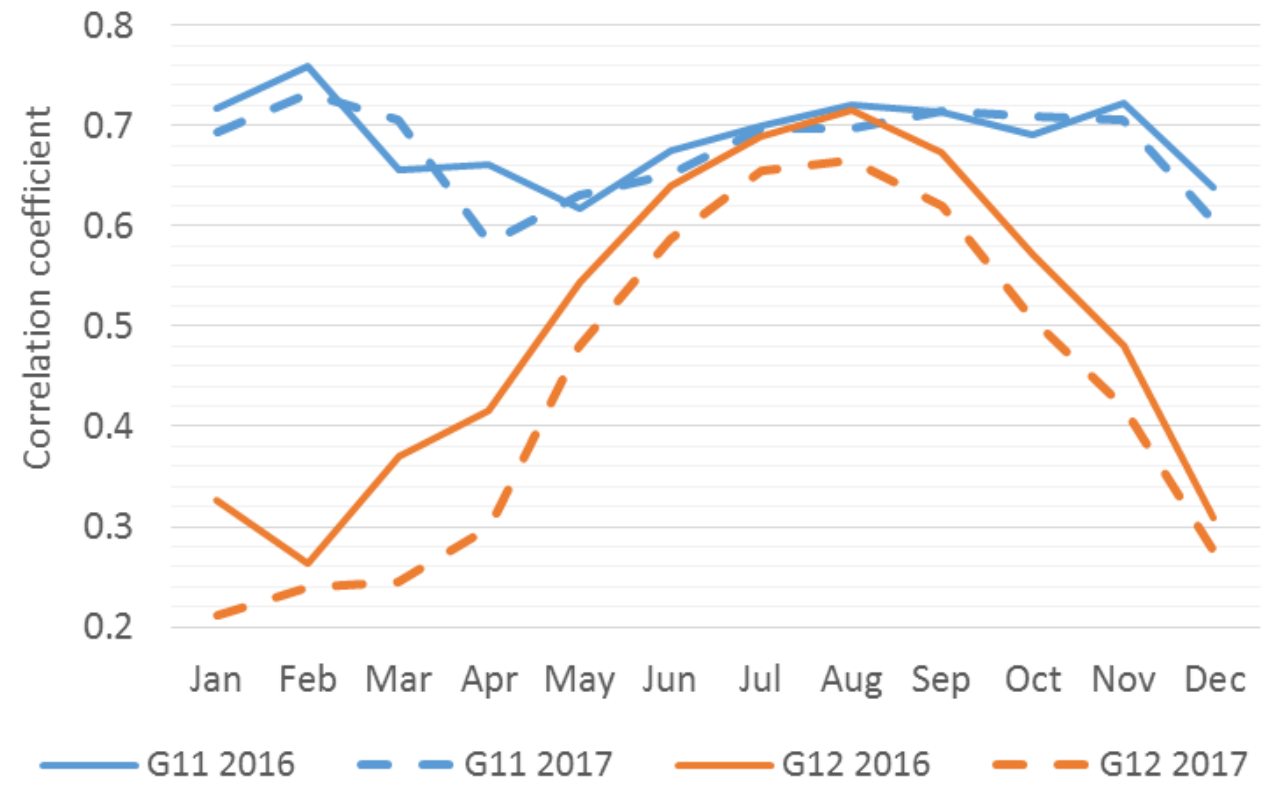

Figure 8. Seasonal variability of Pearson coefficients.

The obtained results concerning the correlation coefficients clearly illustrate the problem of matching the load profiles of residential consumers to the load of the domestic power system, discussed in the following section.

\section{Discussion}

The presented assessment of the impact of TOU tariff DSR programs for households analyses the differences in energy consumption in annual, seasonal, and hourly periods, taking into account the expectations of energy suppliers and distribution system operators as well as possible threats to the power system operation safety.

When assessing the analysed program in an annual perspective, it may be noticed that the annual differences in consumption when using the G12 tariff are moderate compared to the G11 tariff. The G12 TOU tariff allows for an average increase in consumption in comparison to the flat settlement of over $12 \%$, as is stated in Table 1 . Such results reflect partly the targets of electricity suppliers seeking to expand their market volume. However, the actual target of energy suppliers is increasing sales during off-peak periods when electricity in the wholesale market is cheaper and reducing sales during peak periods with above-average wholesale prices. These goals are in line with the goals of network operators aiming to reduce the network load during peak periods and to increase the consumption in off-peak periods. The desired increase in consumption in the off-peak zone is about $60 \%$ in relation to the consumption the flat G11 tariff. In the peak zone, despite the increase in settlement prices, an undesirable increase in consumption of about $10 \%$ is noticed in comparison to the G11 tariff. The load increase during the peak period may be of particular concern for network operators responsible for safety of power supply.

The seasonal consumption increases, presented in Table 2, indicate that the higher consumption when using the G12 tariff occurred both in the off-peak zone and in the peak zone. In winter, there is a significant increase in consumption in the off-peak zone of over $70 \%$ compared to the G11 tariff, and the consumption in the peak period also increases by $5 \%$ compared to the G11 tariff. The consumption growth level, which is not significant concerning the space heating needs in Polish conditions, may suggest that electricity is used for space heating purposes only during extreme climatic conditions, while using alternative and less expensive but more polluting energy sources for space heating on a daily basis. In summer, the peak zone consumption is $6 \%$ smaller compared to the G11 consumption, while the off-peak zone consumption is $12 \%$ higher in G12 tariff in relation to the G11 tariff, which may illustrate the proper operation of the G12 TOU tariff shifting the 
use of home appliances to the off-peak zone. However, it is necessary to take into account also the off-peak period duration of the G12 tariff between 13:00 and 15:00, and its impact in shorter periods needs to be analysed.

The results of electricity consumption changes analysis in the peak and off-peak zones during the year and for seasonal periods are confirmed by the analyses of tariff profiles' correlation with the annual power system's load curve. The average annual correlation between the power system's load curve and the G11 tariff profile is approx. 0.687, which proves a high correlation. Thus, a very large number of customers of the G11 tariff significantly influence the shape of the national power system's load curve. The average annual correlation between the power system's load and the G12 tariff's customers' load is approx. 0.256, which indicates a much lower impact of the G12 tariff on the load curve of the whole system. The analysis of seasonal correlation, carried out for individual months, however, indicates the periodic character of tariff and system load profiles' correlation. In the case of the G12 tariff, the degree of correlation of the load profile with the power system's load curve changes much more dynamically throughout the seasons. For the summer months, the correlation is high (even up to 0.68 ), while for the winter months it is very low (even 0.25 in February). However, even in the summer months, the correlation of the G12 profile is lower than that of the G11 profile, which may be explained by lower load in the G12 peak zone in the summer.

In order to assess the impact of G11 and G12 tariff settlement on power system peak consumption, load differences between the two tariff groups during peak load hours of the power system characteristic of summer and winter seasons were analysed. In the case of the G12 tariff, hourly consumption increases in the expected power system's peak load periods were established around $12 \%$ for both summer and winter seasons, which reveals the potential risk of overloading the system as a result of using the G12 tariff in the current structure. The occurrence of certain load increments during the hours of potential threats does not, however, prove the real harmfulness of the G12 tariff's impact, because the system load is created by the entire set of consumers using or not the tariff DSR programs. The consumption increase of the G12 tariff's consumers may be offset by the possible consumption reduction of other consumers in the considered period. The existence of such a mechanism should be indicated by correlation between the TOU customers' load profile and the load profile of the power system for the analysed periods.

The correlation analysis of G11 and G12 tariffs' profiles for peak hours of power system's load for winter periods showed a lower correlation of the G12 tariff than G11 in the winter peak, which proves that there is no negative impact of this TOU tariff's customers on the winter peak load in these periods, except for the period of 18:00-19:00 in 2017. The lower correlation proves the correct fulfilment of the demand side response function, because the peak load of the power system does not coincide with the peak period of the G12 tariff. The higher correlation of the G12 profile in relation to the G11 profile between 18:00 and 19:00 in 2017 reveals the aspects to be considered when modifying the TOU tariff.

For the entire summer peak period, i.e., between 10.00 and 18:00, the G11 tariff shows a negative correlation with the domestic power system's load, while the G12 tariff shows a very low but positive correlation. The negative correlation of the G11 profile may result from the domination of industrial loads in the analysed period with the seasonally lowered household demand in summer. Regardless of the hourly interval considered, the G12 tariff is characterized by higher correlation values than the G11 tariff in the summer peak period despite lower consumption in the peak zone of G12 tariff comparing to G11 indicated in Table 1. The two-hour off-peak zone during the day in the G12 tariff, which coincides with the power system peak period in summer, lowers the tariff's efficiency in this period, and modification of the off-peak prices zone should be considered to limit the consumption within this time interval. In the winter season, the consumption increases between 13:00 and 15:00 are not significant due to different peak load periods of the power system. In order to increase the TOU tariffs' effectiveness for residential consumers, it would be 
necessary to modify the duration of the peak zones of these tariffs in the summer. The need to introduce such changes would depend on TSO's availability of other efficient measures to balance the power system during summer peak loads, as serious threats to the system stability may occur and could be observed in Poland in $2015[7,8]$.

The presented results are based on statistical data available for the years 2016 and 2017. The noticeable differences of the results obtained from one year to another reflect the overall assessment accuracy for using the discussed methods taking into account the yearly changes in the numbers of consumers in particular tariff groups and trends in their energy consumption. The study presents a design approach towards tariff structure and its assessment based on the best accessible data sets considering the average values for a year, which is also the period of tariff validity accepted by the regulatory authorities. The influence of input parameters changes on the obtained results may be developed in the future research based on more accurate data concerning the customer numbers in tariff groups and their consumption profiles if more accurate data from advanced metering infrastructure becomes available.

The performed analysis concerned the tariff programs used in practice. It would be interesting to use such an approach to analyse the impact of newly designed tariffs on the periods of peak loads occurring in the power system. The key issue in such analyses would be obtaining an approximate load profile of the newly designed tariff, which could be determined based on customers' self and cross price elasticity values [30]. In such analyses, it would be possible to reflect the approximate profile of the newly designed tariff and determine its impact comparing to the flat tariff G11, after applying suitable corrections to the currently applicable tariff schemes regarding zonal prices and duration of particular zones.

The moderately higher energy consumption in G12 tariff indicates its present use only for supplementary space heating purposes while using other space heating systems regularly based on other sources like fossil fuels. To make using electricity for space heating more widespread, it would be necessary to provide the customers with more favourable prices in the off-peak zone. Such tariffs could also be used to encourage charging electric vehicles in the off-peak zone. The above-mentioned problems indicate the direction of further research to be undertaken in the area of modification of TOU tariffs in order to improve their impact on the power system and to enhance air quality.

\section{Conclusions}

The subject of the presented analysis is the methodology for assessing the efficiency of zonal tariff in relation to a flat tariff, based on the known price elasticity of the demand of the customers using a TOU tariff and for which average hourly loads profiles are available. The presented methodology may be used for improving effectiveness of a zonal tariff. The efficiency assessment is based on increases and reductions in energy consumption in the peak and off-peak zones resulting from customer's response to a TOU tariff. Significant positive effects grant the positive assessment of the zonal tariff by energy suppliers.

In the case of TOU programs intended for customers who constitute a significant share of the power system's load, the effects of implementing such tariff programs on power system peak hours' load should also be analysed. One of the forms of such assessment may be correlation analysis of load profiles shaped by the tariffs with the power system's load curve. The increase in the correlation coefficients' values for the TOU tariff during peak system load comparing to the flat tariff indicates the need to modify the zonal tariff's parameters in the event of insufficient generation adequacy or transmission congestion within the system at peak hours. In summary, the following practical applications of the presented methods may be listed:

- $\quad$ assessment of TOU tariffs' effectiveness based on statistical data,

- $\quad$ quantitative assessment of TOU tariffs' overall effectiveness as well as their effectiveness in particular price zones, 
- $\quad$ estimation of changes of consumers' response to price signals in various seasons and the discovery of periods when additional equipment destined to be used in low price zones is used in high price zones as well in result of severe climatic conditions deteriorating the TOU tariff's effects,

- disclosure of possible detrimental effects of the consumption profile of TOU tariff consumers on the power system load during the peak period hours and the use of correlation analysis to confirm such an influence of TOU tariff. Such assessment could be the source for resulting indications concerning the needed modifications of analysed tariffs' structure.

The presented study indicates the pathways of the future research, which may include focusing on proposals for TOU tariffs' modifications that allow for increasing their popularity among residential electricity consumers for the sake of reducing the power system peak demand and increasing the electricity use for space heating purposes limiting the air pollution in winter seasons.

Increasing popularity of smart metering systems, which enable determining actual values of correlation coefficient and price elasticity of electricity demand including their sensitivity to changes of customers' participation in different tariff groups during the year based on the average hourly load profiles of the considered tariff users, provides more accurate and complete data for application of the presented method to reach higher efficiency of DSR tariff programs.

Supplementary Materials: The following are available online at https:/ /www.mdpi.com/1996-107 3/14/2/287/s1, Table S1: Standard load profiles for G11 and G12 tariff for 2016, Table S2: Standard load profiles for G11 and G12 tariff for 2017.

Author Contributions: Conceptualization: J.A. and A.W.; methodology: J.A.; validation: J.A. and J.L.; formal analysis: A.W.; investigation: A.W.; writing—original draft preparation: A.W.; writingreview and editing: J.A.; supervision: J.L.; funding acquisition: J.L. All authors have read and agreed to the published version of the manuscript.

Funding: This research was funded by the Institute of Electric Power Engineering of Poznan University of Technology, grant number 0711/SBAD/4455.

Institutional Review Board Statement: Not applicable.

Informed Consent Statement: Not applicable.

Data Availability Statement: The data presented in this study are available in the article and supplementary materials.

Conflicts of Interest: The authors declare no conflict of interest.

\section{References}

1. Directive (EU) 2019/944 of the European Parliament and of the Council of 5 June 2019 on Common Rules for the Internal Market for Electricity and Amending Directive 2012/27/EU. Available online: https:/ /eur-lex.europa.eu/legal-content/EN/TXT/?uri= CELEX\%3A32019L0944 (accessed on 14 December 2020).

2. Directive 2009/72/EC of the European Parliament and of the Council of 13 July 2009 Concerning Common Rules for the Internal Market in Electricity and Repealing Directive 2003/54/EC. Available online: https:/ /eur-lex.europa.eu/legal-content/EN/ALL/ ?uri=celex\%3A32009L0072 (accessed on 14 December 2020).

3. Modliborska, J.; Zagrajek, K.; Paska, J. Assessment of the development of demand side response services in European Union countries. Rynek Energii 2020, 4, 62-69. (In Polish)

4. Poland's National Energy and Climate Plan for the Years 2021-2030; Ministry of the State Assets: Warsaw, Poland, 2019. Available online: https:/ /www.gov.pl/attachment/df8c4c37-808c-44ff-9278-676fb94add88 (accessed on 14 December 2020).

5. IEA. International Energy Agency Energy Statistics. Poland. Available online: https://www.iea.org/countries/poland (accessed on 23 December 2020).

6. Mid-Term Adequacy Forecast. In Detailed Results and Input Data, 2020 ed.; Appendix 1; ENTSO-E: Brussels, Belgium, 2020.

7. Bućko, P.; Sadowska, I.; Miller, A. Analiza funkcjonowania polskiego rynku energii elektrycznej w okresie wprowadzenia stopni zasilania w 2015 roku. Rynek Energii 2016, 2, 3-8. (In Polish) 
8. Andruszkiewicz, J.; Lorenc, J.; Michalski, A.; Borowiak, W. Opportunities of demand flexibility bidding in result of critical peak pricing implementation for low voltage customers in Polish power system. In Proceedings of the 13th International Conference on the European Energy Market (EEM), Porto, Portugal, 6-9 June 2016; pp. 1-5. [CrossRef]

9. Ministry of Climate, Polish Implementation Plan for Resource Adequacy Concerns. Available online: https:/ / ec.europa.eu/ energy /sites/ener/files/polish_implementation_plan_final_courtesy_translation.pdf (accessed on 14 December 2020).

10. TOE. Electricity and Gas Market in Poland; State of 31 March 2020; Report; Towarzystwo Obrotu Energią: Warsaw, Poland, 2020; Available online: https://www.cire.pl/pliki/2/2020/raport_toe_2020.pdf (accessed on 14 December 2020). (In Polish)

11. TGE. Polish Wholesale Electricity Market Operator-Informations. Available online: https://tge.pl/electricity-dam (accessed on 23 December 2020).

12. Electricity Price Statistics. Available online: https://ec.europa.eu/eurostat/statistics-explained/index.php/Electricity_price_ statistics (accessed on 23 December 2020).

13. Yan, X.; Ozturk, Y.; Hu, Z.; Song, Y. A review on price-driven residential demand response. Renew. Sustain. Energy Rev. 2018, 96, 411-419. [CrossRef]

14. Haider, H.T.; See, O.H.; Elmenreich, W. A review of residential demand response of smart grid. Renew. Sustain. Energy Rev. 2016, 59, 166-178. [CrossRef]

15. Polish Transmission System Operator's Demand Side Response Program. Available online: https://www.pse.pl/uslugi-dsrinformacje-ogolne (accessed on 27 October 2020). (In Polish).

16. Komorowska, A.; Benalcazar, P.; Kaszyński, P.; Kamiński, J. Economic consequences of a capacity market implementation: The case of Poland. Energy Policy 2020, 144, 111683. [CrossRef]

17. Jeżyna, B.; Lis, M.; Mesjasz-Lech, A. The DSR scheme in the capacity market of industrial enterprises in Poland-Participation determinants. Energies 2020, 13, 5462. [CrossRef]

18. Chassin, D.P.; Rondeau, D. Aggregate modeling of fast-acting demand response and control under real-time pricing. Appl. Energy 2016, 181, 288-298. [CrossRef]

19. Herter, K. Residential implementation of critical peak pricing of electricity. Energy Policy 2007, 35, 2121-2130. [CrossRef]

20. Sharifi, R.; Fathi, S.H.; Vahidinnasab, V. A review on Demand-side tools in the electricity market. Renew. Sustain. Energy Rev. 2017, 72, 565-572. [CrossRef]

21. Ryś, M.; Wilczyński, A. Examination of energy tariffs' efficiency impact on energy demand. Przegląd Elektrotech. 2006, 9, 82-83. (In Polish)

22. Bergaentzlé, C.; Græsted Jensen, I.; Skytte, K.; Olsena, O.J. Electricity grid tariffs as a tool for flexible energy systems: A Danish case study. Energy Policy 2019, 126, 12-21. [CrossRef]

23. Schulte, I.; Heindl, P. Price and income elasticities of residential energy demand in Germany. Energy Policy 2017, 102, 512-528. [CrossRef]

24. Volland, B.; Tilov, I. Price Elasticities of Electricity Demand in Switzerland: Results from a Household Panel. IRENE Working Paper. Available online: Ftp:/ / sitelftp.unine.ch/RePEc/irn/pdfs/WP18-03.pdf (accessed on 27 October 2020).

25. Labandeira, X.; Labeaga, J.M.; López-Otero, X. A meta-analysis on the price elasticity of energy demand. Energy Policy 2017, 102, 549-568. [CrossRef]

26. Filippini, M. Short- and long-run time-of-use price elasticities in Swiss residential electricity demand. Energy Policy 2011, 39, 5811-5817. [CrossRef]

27. Andruszkiewicz, J.; Lorenc, J.; Weychan, A. Demand Price Elasticity of Residential Electricity Consumers with Zonal Tariff Settlement Based on Their Load Profiles. Energies 2019, 23, 4317. [CrossRef]

28. Silva, S.; Soares, I.; Pinho, C. Electricity residential demand elasticities: Urban versus rural areas in Portugal. Energy 2018, 144, 627-632. [CrossRef]

29. Woo, C.K.; Liu, Y.; Zarnikau, J.; Shiu, A.; Luo, X.; Kahrl, F. Price elasticities of retail energy demands in the United States: New evidence from a panel of monthly data for 2001-2016. Appl. Energy 2018, 222, 460-474. [CrossRef]

30. Andruszkiewicz, J.; Lorenc, J.; Weychan, A. Seasonal variability of price elasticity of demand of households using zonal tariffs and its impact on hourly load of the power system. Energy 2020, 196, 117175. [CrossRef]

31. O'Connell, N.; Pinson, P.; Madsen, H.; O'Malley, M. Benefits and challenges of electrical demand response: A critical review. Renew. Sustain. Energy Rev. 2014, 39, 686-699. [CrossRef]

32. Lijesen, M.G. The real-time price elasticity of electricity. Energy Econ. 2007, 29, 249-258. [CrossRef]

33. Muratori, M.; Schuelke-Leech, B.-A.; Rizzoni, G. Role of residential demand response in modern electricity markets. Renew. Sustain. Energy Rev. 2014, 33, 546-553. [CrossRef]

34. Oualmakran, Y.; Espeche, J.M.; Sisini, M.; Messervey, T.; Lennard, Z. Residential Electricity Tariffs in Europe: Current Situation, Evolution and Impact on Residential Flexibility Markets. Proceedings 2017, 1, 1104. [CrossRef]

35. Yukseltan, E.; Yucekaya, A.; Bilge, A.H. Hourly electricity demand forecasting using Fourier analysis with feedback. Energy Strategy Rev. 2020, 31, 100524. [CrossRef]

36. Kantor, I.; Rowlands, I.H.; Parker, P. Aggregated and disaggregated correlations of household electricity consumption with time-of-use shifting and conservation. Energy Build. 2017, 139, 326-339. [CrossRef]

37. Vom Scheidt, F.; Medinová, H.; Ludwig, N.; Richter, B.; Staudt, P.; Weinhardt, C. Data analytics in the electricity sector-A quantitative and qualitative literature review. Energy AI 2020, 1, 100009. [CrossRef] 
38. Fan, C.; Xiao, F.; Wang, S. Development of prediction models for next-day building energy consumption and peak power demand using data mining techniques. Appl. Energy 2014, 127, 1-10. [CrossRef]

39. Kadam, S.; Bletterie, B.; Gawlik, W. A Large Scale Grid Data Analysis Platform for DSOs. Energies 2017, 10, 1099. [CrossRef]

40. Kim, M.-J. Determining the Relationship between Residential Electricity Consumption and Factors: Case of Seoul. Sustainability 2020, 12, 8590. [CrossRef]

41. Parizy, E.S.; Ardakani, A.J.; Mohammadi, A.; Loparo, K.A. A new quantitative load profile measure for demand response performance evaluation. Int. J. Electr. Power Energy Syst. 2020, 121, 106073. [CrossRef]

42. EMA. Statistics of Polish Power Engineering 2016; Energy Market Agency: Warsaw, Poland, 2017. (In Polish)

43. EMA. Analysis of the Profitability of Tariff Groups at High, Medium and Low Voltage in Trading Enterprises and Enterprises Dealing with Electricity Distribution in, Energy Market Agency; Study prepared for the order of the Institute of Electric Power Engineering at Poznan University of Technology; EMA: Warsaw, Poland, 2017. (In Polish)

44. Act of 10th April 1997-Energy Law, Dz.U. 1997 nr 54 poz. 348. Available online: http:/ /isap.sejm.gov.pl/isap.nsf/download. xsp/WDU19970540348/U/D19970348Lj.pdf (accessed on 27 October 2020). (In Polish)

45. Enea Operator Sp. z o.o. Grid Code: Standard Load Profiles. Available online: https://www.operator.enea.pl/dladomu/ uslugidystrybucyjne/iriesd (accessed on 27 October 2020). (In Polish).

46. URE. Tariff for Electricity Customers from G Tariff Groups in 2016, Enea, S.A. Decision of the President of the Energy Regulatory Office no. DRE-4211-51(7)/2015/2688/IX/KKu/MDę of 17 December 2015. Available online: http://bip.ure.gov.pl/download/ 3/6762/20151217TaryfaENEASA.pdf (accessed on 27 October 2020).

47. URE. Tariff for Electricity Customers from G Tariff Groups in 2017, Enea, S.A. Decision of the President of the Energy Regulatory Office no. DRE.WRE.4211.24.8.2016.AKo of 15 December 2016. Available online: http://bip.ure.gov.pl/download/3/8638/20161 215TaryfaENEASA.pdf (accessed on 27 October 2020).

48. URE. Tariff for Electricity Distribution Services in 2016, Enea Operator, Decision of the President of the Energy Regulatory Office no. DRE-4211-63(1)/2015/13854/IX/KKu/MDe of 17 December 2015. Available online: http://bip.ure.gov.pl/download/3/67 63/20151217TaryfaENEAOperatorSA.pdf (accessed on 27 October 2020).

49. URE. Tariff for Electricity Distribution Services in 2017, Enea Operator, Decision of the President of the Energy Regulatory Office no. DRE.WRE.4211.25.8.2016.AKo of 15 December 2016. Available online: http://bip.ure.gov.pl/download/3/8637/2016121 5TaryfaENEAOperatorSpzoo.pdf (accessed on 27 October 2020).

50. Raporty Dobowe z Pracy KSE, Wielkości Podstawowe. Available online: https://www.pse.pl/dane-systemowe/funkcjonowaniekse/raporty-dobowe-z-pracy-kse/wielkosci-podstawowe (accessed on 27 October 2020). 